\title{
Correction to: Ocular manifestations in celiac disease: an overview
}

\author{
Fotios S. Fousekis • Andreas Katsanos • Konstantinos H. Katsanos • \\ Dimitrios K. Christodoulou
}

Published online: 2 April 2020

(C) Springer Nature B.V. 2020

\section{Correction to:}

\section{Int Ophthalmol}

https://doi.org/10.1007/s10792-019-01254-x

In the original publication, first line of methods under the Abstract section was published incorrectly. The correct version should read as "A thorough review of the literature was performed using PubMed to identify articles about ocular manifestations of celiac disease."

Publisher's Note Springer Nature remains neutral with regard to jurisdictional claims in published maps and institutional affiliations.

The original article can be found online at https:// doi.org/10.1007/s10792-019-01254-x.

F. S. Fousekis · K. H. Katsanos •

D. K. Christodoulou ( $\square)$

Department of Gastroenterology and Hepatology, School of Health Sciences, University Hospital of Ioannina, University of Ioannina, 45100 Ioannina, Greece e-mail: dchristodoulou@gmail.com

F. S. Fousekis

e-mail: fotisfous@gmail.com

K. H. Katsanos

e-mail: khkostas@hotmail.com

A. Katsanos

Department of Ophthalmology, School of Health

Sciences, University Hospital of Ioannina, University of

Ioannina, Ioannina, Greece

e-mail: andreakatbp@hotmail.com 